\title{
Persistent Brain Herniation after Decompressive Hemicraniectomy: Role of Lumbar Drainage for Cranioplasty. Case Report
}

\author{
Mario Francesco Fraioli ${ }^{*}$, Francesco Marzetti1 ${ }^{1}$ Bernardo Fraioli ${ }^{2}$, Pierpaolo Lunardi ${ }^{1}$ \\ ${ }^{1}$ Department of Neurosciences, University of Rome Tor Vergata, Rome, Italy \\ ${ }^{2}$ Department of Diagnostic for Imaging, Cirad Villa Benedetta of Rome, Rome, Italy \\ Email: "mff77@libero.it
}

Received 5 January 2016; accepted 21 January 2016; published 25 January 2016

Copyright (C) 2015 by authors and OALib.

This work is licensed under the Creative Commons Attribution International License (CC BY).

http://creativecommons.org/licenses/by/4.0/

(c) (i) Open Access

\begin{abstract}
Hydrocephalus and ex-vacuo ventricular dilatations which cause persistent brain herniation with impossibility to perform cranioplasty, are well known late complications after decompressive hemicraniectomy; concerning the physiopathologic mechanism leading to these complications, there are several theories. We report the particular case of a patient suffering from persistent brain herniation after decompressive hemicraniectomy, due to development of subdural hygroma, intraparenchymal multiple liquoral cysts and only mild enlargement of frontal horn of right lateral ventricle. A fifty-five years old male patient was treated with decompressive right hemicraniectomy for acute hemispheric swelling consequent to right internal carotid artery dissecation. After several months, evaluating the patient for cranioplasty, brain herniation was clinically evident and brain MRI confirmed it due to subdural hygroma, intraparenchymal multiple liquoral cysts and mild enlargement of frontal horn of right lateral ventricle. According to several reported theories, communication between right frontal horn of lateral ventricle, intraparenchymal liquoral cysts and subdural hygroma was supposed, and CSF lumbar drainage was placed. Regression of brain herniation was achieved and cranioplasty was possible; after few days lumbar drainage was removed: neither operative, nor short and long follow-up period complications were observed. Temporary CSF lumbar drainage resulted effective to obtain regression of a particular case of persistent brain herniation developed after decompressive hemicraniectomy; moreover this safe procedure, not previously described to forerun cranioplasty surgery to our knowledge, allowed performing cranioplasty in absence of complications and avoiding temporary or permanent ventricular shunts which present a major rate of risks and possible complications.
\end{abstract}

\section{Keywords}

Decompressive Hemicraniectomy, Persistent Brain Herniation, Lumbar Drainage, Cranioplasty

\footnotetext{
*Corresponding author.
}

How to cite this paper: Fraioli, M.F., Marzetti, F., Fraioli, B. and Lunardi, P. (2016) Persistent Brain Herniation after Decompressive Hemicraniectomy: Role of Lumbar Drainage for Cranioplasty. Case Report. Open Access Library Journal, 3: e2346. http://dx.doi.org/10.4236/oalib.1102346 


\section{Subject Areas: Neurology, Surgery \& Surgical Specialties}

\section{Introduction}

Decompressive hemicraniectomy represents a life saving treatment for malignant intracranial hypertension caused by multiple pathologies, as hemispheric cerebral infarction, nontraumatic intraparenchymal hemorrhage, aneurysmal subarachnoid hemorrhage, and venous sinus thrombosis [1]-[4]. This surgical procedure includes several complications like infections, wound dehiscence and post-operative CSF leak, epidural hemorrhage [5], bone resorption [6], and epilepsy [7]; moreover, communicating hydrocephalus and ex-vacuo ventricular dilatations [8], which often require permanent ventricular CSF shunt after bone flap replacement [9], can occur. Many authors have debated about the physiopathology of hydrocephalus after ischemic infarction [10] and about the timing of cranioplasty to prevent this complication [11]. We report the perioperative management and the surgical technique of a patient previously submitted to decompressive hemicraniectomy for malignant hemispheric ischemia due to right middle cerebral artery (MCA) obstruction, who developed a particular persistent brain herniation due to the development of subdural hygroma and multiple intraparenchymal CSF cysts with mild dilatation of the frontal horn of right lateral ventricle.

\section{Case Presentation}

A 55 years old male patient had suffered for a right acute hemispheric malignant ischemia caused by right internal carotid artery (ICA) dissecation and consequent right MCA (M1, M2, M3) obstruction, with severe left hemyparesis and coma state due to the consequent massive brain hemispheric swelling. Therefore, he had been treated with a decompressive right hemispheric craniectomy, reacquiring a normal status of consciousness, with permanence of severe left hemiparesis. Because of successive prolonged pulmonary infections, evaluation for cranioplasty was possible only 7 months after surgery, but brain MRI showed the presence of subdural hygroma and multiple intraparenchymal CSF cysts in the right malacic cerebral hemisphere with brain herniation from the craniotomic gap, associated to only mild ex-vacuo dilatation of the frontal horn of the right lateral ventricle; communication between CSF cysts, subdural hygroma, and frontal horn of right lateral ventricle was supposed, according to the MRI (Figure 1).

The patient was first treated with high dosage diuretic therapy without any improvement after several weeks, and cutaneous flap was yet stretched and bulging. Therefore, after nine months from hemicraniectomy, in absence of improvement after diuretic therapy, the patient was admitted to our hospital to consider the necessary treatments for the execution of cranioplasty. Positioning of CSF lumbar drainage was performed, observing an initial pressure of $16 \mathrm{~cm} \mathrm{H}_{2} \mathrm{O}$; then, $100 \mathrm{ml} /$ die were drained for 3 days before surgery, and daily head bandage to reduce brain herniation was performed. A control brain MRI, after 2 days of drainage, showed a clear volume reduction of CSF cysts and subdural hygroma with reduction of the ventricular frontal horn of lateral ventricle, too; moreover, cutaneous flap became flaccid and concave, and brain herniation regressed. Control of liquoral pressure from lumbar catheter resulted $10 \mathrm{~cm} \mathrm{H}_{2} \mathrm{O}$. This result confirmed the presence of communication between CSF intraparenchymal cysts, subdural hygroma and frontal horn of right lateral ventricle (Figure 2). At surgical operation for cranioplasty, great care was taken during initial dissection of tissue planes, to avoid hemispheric CSF leak and exposition of cortical surface, so reducing the risk of infection and presence of liquor under the cutaneous flap with possible consequent wound dehiscence. Cranioplasty was performed with a 165 $\mathrm{cm}^{2}$ Medpor titanium implant fixed to the skull using titanium plates and screws. Lumbar drainage was maintained after surgery, draining $100 \mathrm{ml} /$ die to keep a low constant CSF pressure, to make an adaptation to cranioplasty; after three days, the lumbar drainage was closed, clinical status remained unchanged and in fifth postoperative day a control brain MRI was performed, showing no signs of brain compression and no enlargement of ventricular system, and stability of residual mild subdural hygroma and CSF cysts (Figure 3). Five days after surgery, CSF pressure was $12 \mathrm{~cm} \mathrm{H}_{2} \mathrm{O}$. Consequently, lumbar drainage was removed. Neither external ventricular drainage, nor other internal CSF shunts were required intraoperatively or after the procedure, as other authors reported in their experience [7]. The patient didn't show any operative, post-operative or late complications and any MRI differences were registered after a follow-up period of 2.5 years. 

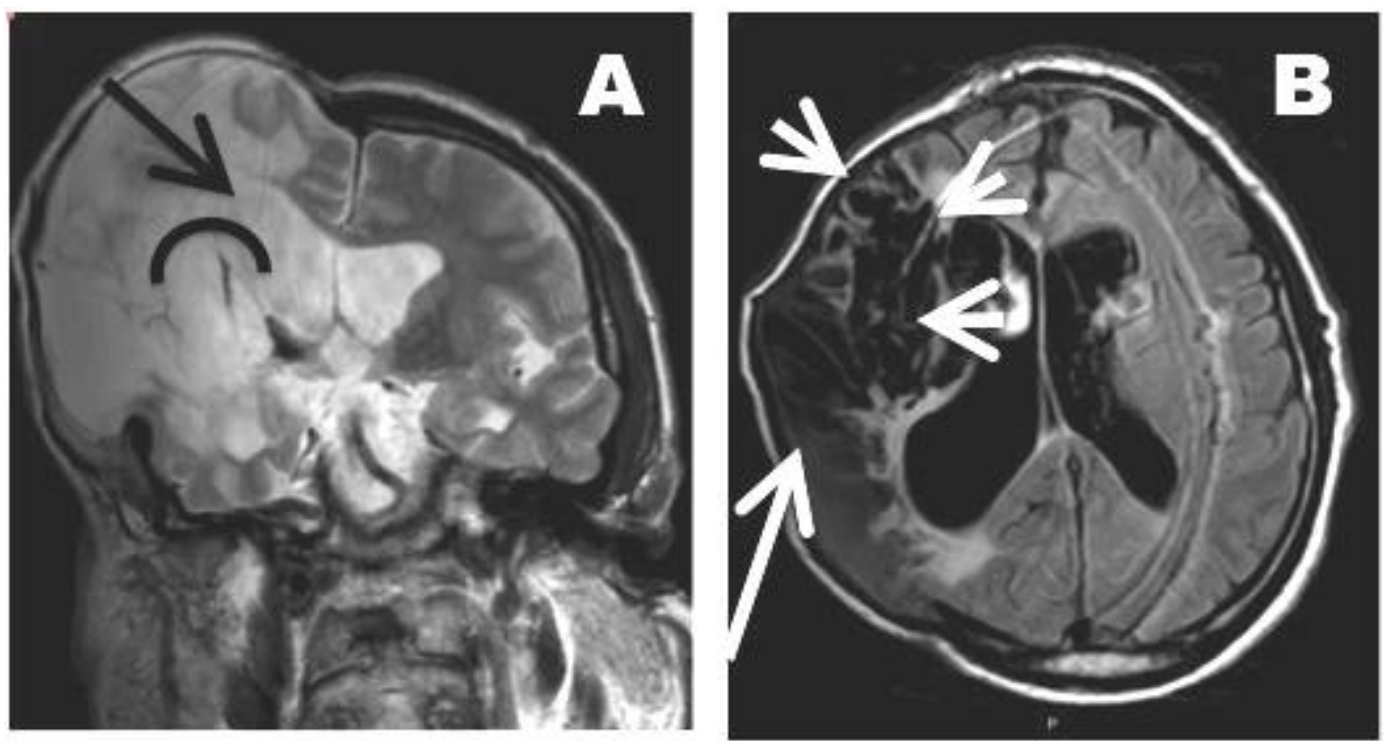

Figure 1. Preoperative MRI. MRI showing complications 9 months after decompressive hemicraniectomy: subdural hygroma, intraparenchymal liquoral cysts and a mild enlargement of frontal horn of right lateral ventricle. (A) T2 weighted coronal slice, in which a mild dilatation of the frontal horn of right lateral ventricle is evident (black arrow); the black curved line shows the supposed communication between ventricle and cortical arachnoid spaces due to damage of the ventricular ependyma; (B) T2 (FLAIR) weighted axial slice, with evidence of subdural hygroma (white arrow) and intraparenchymal liquoral cysts (white arrow heads).
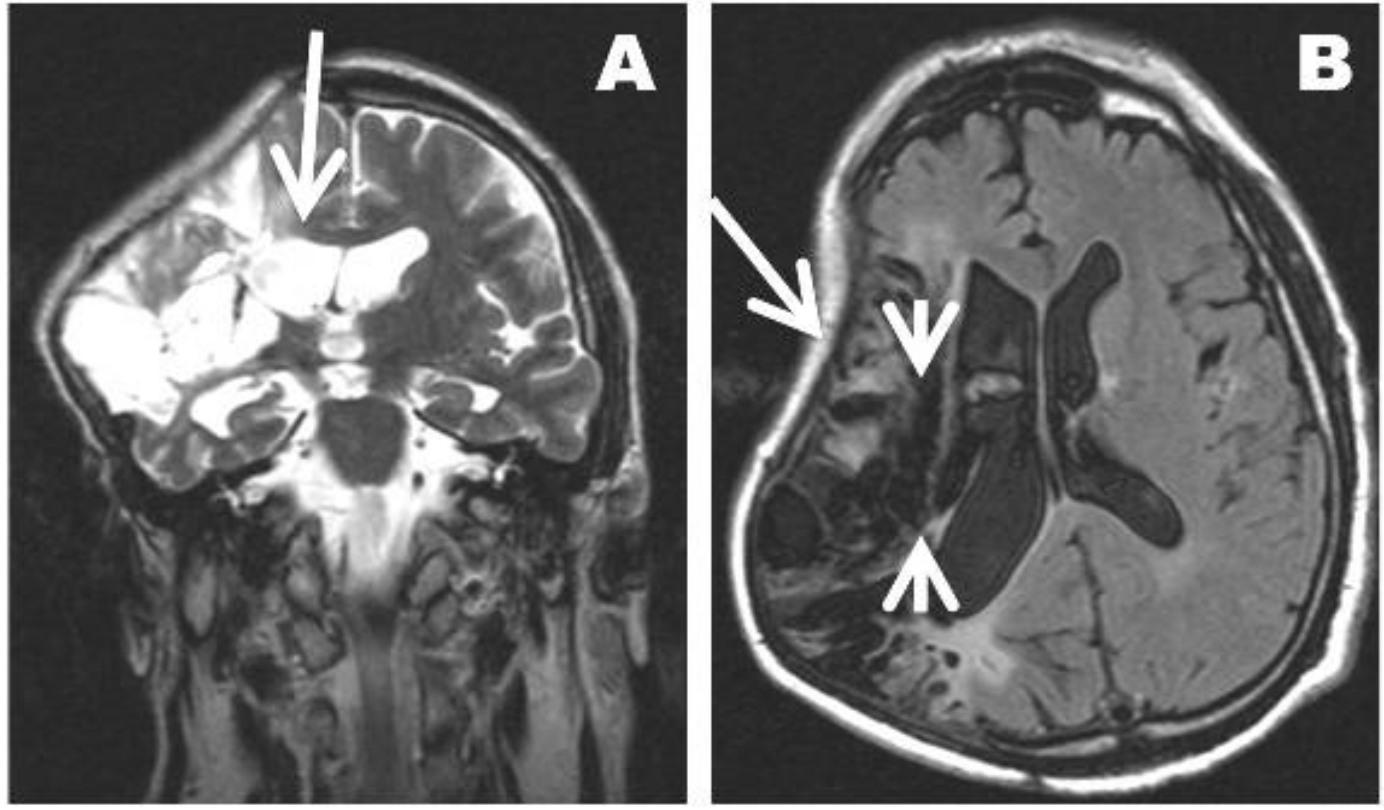

Figure 2. MRI after positioning of CSF lumbar drainage. MRI performed 2 days after positioning of CSF lumbar drainage, draining $100 \mathrm{ml} /$ die. (A) T2 weighted coronal slice, with evidence of right frontal horn of lateral ventricle volume reduction (black arrow); (B) T2 (FLAIR) weighted axial slice, showing resorption of subdural hygroma (white arrow) and marked volume reduction of intraparenchymal liquoral cysts (white arrow heads).

\section{Discussion}

\subsection{Persistent Brain Herniation after Decompressive Hemicraniectomy}

In our reported case we observed a persistent brain herniation until one year after surgery; this particular condi- 


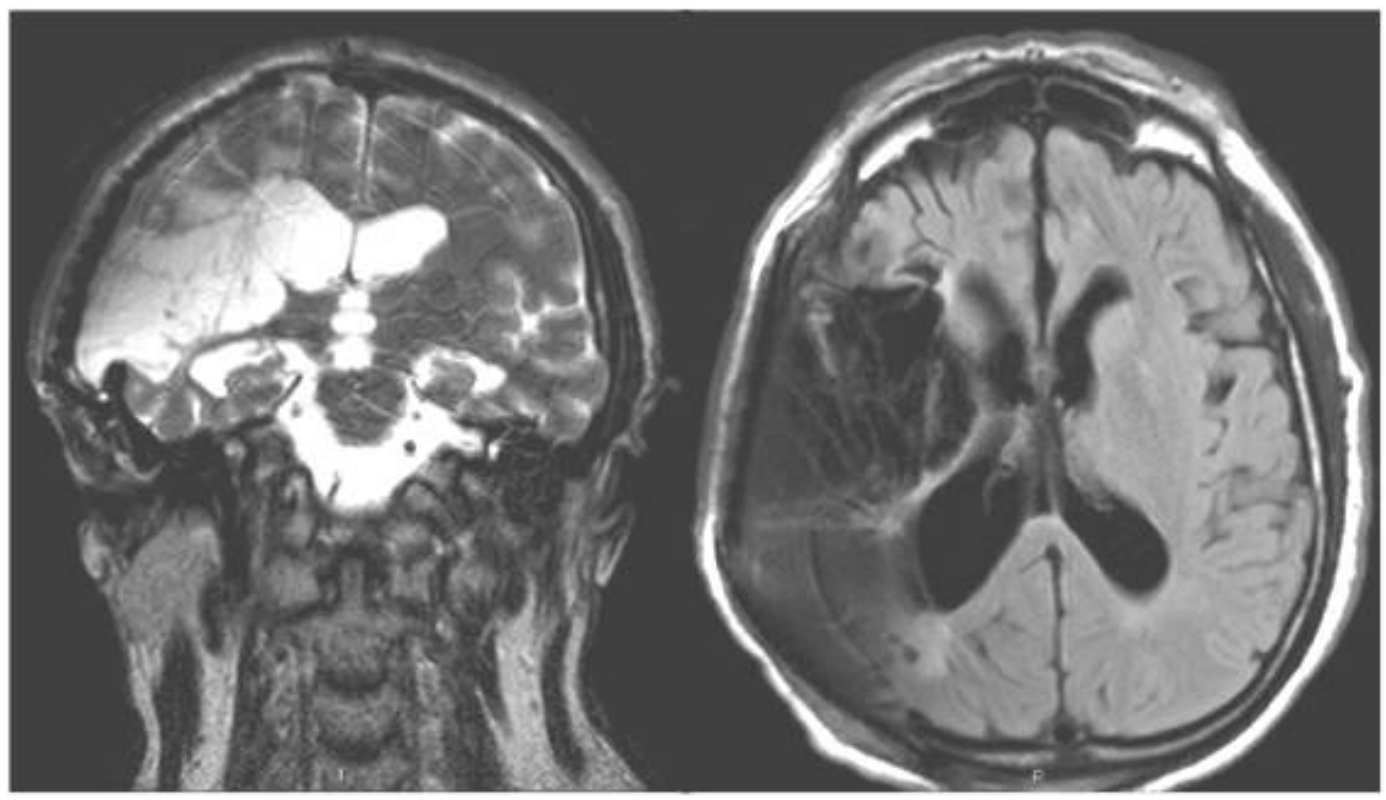

Figure 3. MRI after cranioplasty. MRI performed after cranioplasty and after closure of CSF lumbar drainage; a slight final ex-vacuo enlargement of the frontal horn of right lateral ventricle is visible, as well as a slight ex-vacuo enlargement of intraparenchymal CSF spaces; the postoperative final volume of these liquoral spaces is clearly smaller than the pre-treatment one.

tion was due to the contemporary presence of subdural hygroma, marked CSF spaces dilatations (liquoral cysts) and slight enlargement of homolateral frontal horn of lateral ventricle. This occurrence can be explained, in our opinion and according to neuroradiologist, by a pathological anatomic modification subsequent to hemispheric ischemia leading to an ependymal damage with communication between the right frontal horn of lateral ventricle and the described CSF enlarged intersulcal spaces. Regarding the pathologic mechanism by which hydrocephalus/ventricular dilatation and CSF intraparenchymal spaces dilatation develop after hemicraniectomy, it remains to be determined. Some authors [12] described failure of ependymal regeneration after acquired damage due to some events as massive ischemia or hemorrhagic infarction, infections and other inflammatory conditions with consequent interruption of the ventricular wall integrity. Other authors [10] supposed that factors such as post-surgical inflammation or mechanical blockage of arachnoid granulation can cause a decrease of CSF outflow; we agree with the supposition that the "flattening" of the normal dicrotic ICP waveform in patient monitored after hemicraniectomy, due to the trasmission of the pressure pulse out of the open cranium, can cause a decreased CSF outflow, because the arachnoid granulations function as pressure-dependent one-way valves from the subarachnoid space to the draining venous sinuses. In our patient, according to the above-mentioned mechanisms, hemispheric ischemia probably generated a pathological communication between right ventricle and CSF intersulcal spaces; then, the prolonged lack of bone flap generated an increase of liquoral pressure because of decreased CSF outflow, causing intersulcal hemispheric CSF spaces dilatation and subdural hygroma.

\subsection{Utility and Indications of Temporary CSF Lumbar Drainage; Timing and Operative Devices for Cranioplasty}

Temporary CSF lumbar drainage apposition allowed in our patient to eliminate brain herniation, draining daily $100 \mathrm{ml}$ of CSF for three days; moreover, it allowed: to perform cranioplasty avoiding cranial CSF shunts and to restore adeguate CSF flow after cranioplasty. Measurement of CSF pressure from lumbar catheter revealed high value before insertion of lumbar drainage $\left(16 \mathrm{~cm} \mathrm{H}_{2} \mathrm{O}\right)$, and lower one $\left(10 \mathrm{~cm} \mathrm{H}_{2} \mathrm{O}\right)$; CSF pressure measurement five days after cranioplasty (two days after closure of lumbar drainage), revealed normal value $\left(12 \mathrm{~cm}_{2} \mathrm{O}\right)$.

Concerning the timing and the expedients for cranioplasty, some authors recommend early cranioplasty [13], others [7] recommend intraoperative CSF drain with apposition of an external ventricular derivation to avoid or to treat the occurrence of post-surgical hydrocephalus and other parenchymal CSF collections. In our experience, 
precocious cranioplasty can expose patients to higher risk of infections, and in particular in the reported case cranioplasty was not precociously performable because of pulmonary protracted infection; moreover, external ventricular drainage is not free from possible complications. So that, an attempt with a lumbar drainage, in our opinion can be performed because it is located far from the cranial surgical site, it is less invasive and complications are very rare [14]; moreover, it doesn't preclude other possibilities, because it can be maintained during the postoperative period, and if hydrocephalus and/or CSF sulcal spaces dilatation occur after its closure, it can be opened and a permanent ventricular shunt can be placed. It is clear that lumbar drainage is not indicated in case of intraparenchymal CSF cysts and/or subdural hygroma not communicating with the ventricular system.

\section{Conclusion}

Temporary CSF lumbar drainage resulted effective to obtain regression of a particular case of persistent brain herniation, developed after decompressive hemicraniectomy, caused by intraparenchymal CSF cysts, subdural hygroma communicating with ventricular system and mild ventricular enlargement; moreover, this safe procedure, not previously described to forerun cranioplasty surgery to our knowledge, allowed performing cranioplasty in absence of complications and avoiding temporary or permanent ventricular shunts.

\section{References}

[1] Coutinho, J.M., Majoie, C.B., Coert, B.A. and Stam, J. (2009) Decompressive Hemicraniectomy in Cerebral Sinus Thrombosis: Consecutive Case Series and Review of the Literature. Stroke, 40, 2233-2235. http://dx.doi.org/10.1161/STROKEAHA.108.543421

[2] Tuzgen, S., Kucukyuruk, B., Aydin, S., Ozlen, F., Kizilkilic, O. and Abuzayed, B. (2012) Decompressive Craniectomy in Patients with Cerebral Infarction Due to Malignant Vasospasm after Aneurysmal Subarachnoid Hemorrhage. Journal of Neurosciences in Rural Practice, 3, 251-255. http://dx.doi.org/10.4103/0976-3147.102598

[3] Yoo, S.H., Kim, T.H., Shin, J.J., Hwang, Y.S. and Park, S.K. (2012) The Clinical Efficacy of Decompressive Craniectomy in Patients with an Internal Carotid Artery Territory Infarction. Journal of Korean Neurosurgical Society, 52, 293-299. http://dx.doi.org/10.3340/jkns.2012.52.4.293

[4] Yu, J.W., Choi, J.H., Kim, D.H., Cha, J.K. and Huh, J.T. (2012) Outcome Following Decompressive Craniectomy for Malignant Middle Cerebral Artery Infarction in Patients Older Than 70 Years Old. Journal of Cerebrovascular and Endovascular Neurosurgery, 14, 65-74. http://dx.doi.org/10.7461/jcen.2012.14.2.65

[5] De Bonis, P., Frassanito, P., Mangiola, A., Nucci, C.G., Anile, C. and Pompucci, A. (2012) Cranial Repair: How Complicated Is Filling a "Hole"? Journal of Neurotrauma, 29, 1071-1076. http://dx.doi.org/10.1089/neu.2011.2116

[6] Schuss, P., Vatter, H., Oszvald, A., Marquardt, G., Imöhl, L., Seifert, V. and Güresir, E. (2013) Bone Flap Resorption: Risk Factors for the Development of a Long-Term Complication Following Cranioplasty after a Decompressive Craniectomy. Journal of Neurotrauma, 30, 91-95. http://dx.doi.org/10.1089/neu.2012.2542

[7] Oh, C.H., Park, C.O., Hyun, D.K., Park, H.C. and Yoon, S.H. (2008) Comparative Study of Outcomes between Shunting after Cranioplasty and in Cranioplasty after Shunting in Large Concave Flaccid Cranial Defect with Hydrocephalus. Journal of Korean Neurosurgical Society, 44, 211-216. http://dx.doi.org/10.3340/jkns.2008.44.4.211

[8] Li, G., Wen, L., Zhan, R.Y., Shen, F., Yang, X.F. and Fu, W.M. (2008) Cranioplasty for Patients Developing Large Cranial Defects Combined with Post-Traumatic Hydrocephalus after Head Trauma. Brain Injury, 22, 333-337. http://dx.doi.org/10.1080/02699050801958353

[9] Carvi, Y., Nievas, M.N. and Höllerhage, H.G. (2006) Early Combined Cranioplasty and Programmable Shunt in Patients with Skull Bone Defects and CSF-Circulation Disorders. Neurological Research, 28, 139-144. http://dx.doi.org/10.1179/016164106X98008

[10] Waziri, A., Fusco, D., Mayer, S.A., Mayer, S.A., McKhann 2nd, G.M. and Connolly Jr, E.S. (2007) Postoperative Hydrocephalus in Patients Undergoing Decompressive Hemicraniectomy for Ischemic or Hemorrhagic Stroke. Neurosurgery, 61, 489-494. http://dx.doi.org/10.1227/01.NEU.0000290894.85072.37

[11] Schuss, P., Vatter, H., Marquardt, G., Imöhl, L., Ulrich, C.T., Seifert, V. and Güresir, E. (2012) Cranioplasty after Decompressive Craniectomy: The Effect of Timing on Postoperative Complications. Journal of Neurotrauma, 29, 1090 1095. http://dx.doi.org/10.1089/neu.2011.2176

[12] Sarnat, H.B. (1995) Ependymal Reactions to Injury. A Review. Journal of Neuropathology \& Experimental Neurology, 54, 1-15. http://dx.doi.org/10.1097/00005072-199501000-00001

[13] Piedra, M.P., Ragel, B.T., Dogan, A., Coppa, N.D. and Delashaw, J.B. (2013) Timing of Cranioplasty after Decompressive Craniectomy for Ischemic or Hemorrhagic Stroke. Journal of Neurosurgery, 118, 109-114. 
http://dx.doi.org/10.3171/2012.10.JNS121037

[14] Governale, L.S., Fein, N., Logsdon, J. and Black, P.M. (2008) Techniques and Complications of External Lumbar Drainage for Normal Pressure Hydrocephalus. Neurosurgery, 63, 379-384.

http://dx.doi.org/10.1227/01.neu.0000327023.18220.88 